\title{
Effect of the synthetic glucocorticoid, deflazacort, on body growth, pulsatile secretion of GH and thymolysis in the rat
}

\author{
Kay Latta, Richard J Krieg J ${ }^{1}$, Satoshi Hisano, Johannes D Veldhuis ${ }^{2}$ and James C M Chan \\ Departments of Pediatrics and ${ }^{1}$ Anatomy, M edical College of Virginia, Richmond, Virginia, USA and ${ }^{2}$ Department of Internal M edicine, \\ Division of Endocrinology, University of Virginia, Charlottesville, Virginia, USA \\ (Correspondence should be addressed to K Latta who is now at Kinderklinik der M HH, Carl-Neuberg Str. 1, 30625 Hannover, Germany)
}

\begin{abstract}
Design: Deflazacort (DFZ) is a relatively new glucocorticoid that has been reported to exhibit fewer sideeffects than other commonly used corticosteroids. The present study was designed to test the effects of DFZ on thymus gland involution (thymolysis), as compared with body growth and the secretory pattern of $\mathrm{GH}$ in the rat. Beginning at 38 days of age, male animals were treated for 8 consecutive days by s.c. injection of DFZ ( $0.15 \mathrm{mg} /$ day), cortisone (CORT) $(5 \mathrm{mg} /$ day) or vehicle (control, CTRL).

Results: Both glucocorticoids had a similar thymolytic effect and caused growth failure, but the growth rate for the DFZ group was significantly higher than that of the CORT group. On day 46, pulsatile GH secretion was quantitated by blood sampling via an indwelling catheter at $10 \mathrm{~min}$ intervals for $6 \mathrm{~h}$. GH was assayed by RIA and analyzed by multiparameter deconvolution. CORT caused an increase in pulse frequency $(5.8 \pm 0.4$ (S.E.M.)) in comparison to DFZ $(4.4 \pm 0.4)$ and CTRL $(3.8 \pm 0.3)$. Both glucocorticoids significantly shortened the interval between secretory bursts. In CTRL animals the interval between bursts was $69.3 \pm 4.5 \mathrm{~min}$. In DFZ animals this was reduced to $58.5 \pm 7.1 \mathrm{~min}$, and in CORT rats it was further reduced to $47.0 \pm 2.6 \mathrm{~min}$. The mass of $\mathrm{GH}$ secreted per burst was reduced in CORT animals ( $52 \%$ of CTRL), while DFZ did not alter this parameter. A similar trend was observed for total GH production, with CORT causing a reduction and DFZ not affecting the secretion.

Conclusion: Rats treated with glucocorticoid show a profound thymolytic effect, as well as important changes in growth. While CORT suppresses GH secretion and alters its pulsatile mode of release, DFZ causes a less significant alteration in the pattern of GH secretion and does not negatively affect the overall amount of $\mathrm{GH}$ secreted.
\end{abstract}

European Journal of Endocrinology $140441-446$

\section{Introduction}

In children, daily treatment with corticosteroids inhibits growth in a dose-dependent fashion when used for a prolonged period of time (1-3). Growth inhibition by corticosteroids has also been demonstrated in rats (4-6).

In the complete absence of glucocorticoids, growth hormone $(\mathrm{GH})$ production is low $(7,8)$. It increases with the addition of thyroxine and low doses of glucocorticoids in vivo and in vitro $(9-11)$. While short-term application of glucocorticoids stimulates $\mathrm{GH}$ secretion in vitro (12-14) and in vivo (15), as measured by standardized stimulation tests $(16,17)$, prolonged exposure to glucocorticoids has negative effects on $\mathrm{GH}$ secretion in vivo $(16,18)$. After cessation of cortisone (CORT) treatment, increased secretion of $\mathrm{GH}$ with concomitant failure of catch-up growth has been observed in rats (19).

In 1967 Nathansohn et al. (20) synthesized a novel corticosteroid, deflazacort (DFZ), which is an oxazoline derivative of CORT. In rats, DFZ has a plasma half-life of $1.1 \mathrm{~h}$ for the alpha-phase and $11.6 \mathrm{~h}$ for the beta-phase
$(21-23)$. DFZ is metabolized in the liver to at least five different compounds, although the oxazoline group is not known to undergo degradation or metabolism in any species (22). DFZ is less lipophilic than other glucocorticoids (24), and therefore less likely to permeate into the brain (25). Assuming that glucocorticoids act in part upon central nervous system control mechanisms, it might be expected that DFZ would exert less influence on $\mathrm{GH}$ secretion by having less access to the brain. However, no data exist regarding the effects of DFZ on pulsatile GH secretion.

Immunosuppressive and anti-inflammatory properties of DFZ have been demonstrated in animals (26). At comparable dosages, DFZ was associated with less growth retardation than other corticosteroids in children with different diseases (27-30) and in rats (31). Studies on comparable dosages show a ratio of 1:31$1: 33$ for DFZ to CORT in vivo in rats $(31-35)$. These bioequivalence studies are based on carrageenin- and nystatin-induced edema, thymolytic effects, and the ex vivo binding to glucocorticoid receptors of various glucocorticoids. Humans are less sensitive to DFZ with a 
dosage ratio of $1: 1.2$ for prednisone to DFZ (equivalent to about 1:3.3 for DFZ to CORT $(36,37)$ ). The present studies were designed to test the effects of CORT and DFZ on thymolysis, growth and the pulsatile mode of $\mathrm{GH}$ secretion in animals receiving this treatment.

\section{Materials and methods}

Thirty-seven male Long Evans rats (Charles River Laboratories, Wilmington, MA, USA) at 32 days of age were assigned to three weight-matched groups as follows: CORT ( $5.0 \mathrm{mg} /$ day, $\mathrm{n}=12)$, DFZ $(0.15 \mathrm{mg} /$ day, $n=12)$ and control (CTRL, vehicle, $n=12)$. The rats were placed in single cages. Animals were housed in a $12 \mathrm{~h}$ light: $12 \mathrm{~h}$ darkness cycle with the lights on at $0700 \mathrm{~h}$ and off at $1900 \mathrm{~h}$.

Starting at 38 days of age the animals received the respective glucocorticoid or vehicle for 8 consecutive days. CORT was supplied as cortisone-acetate in a $0.9 \%$ benzyl alcohol solution. Generic crystalline DFZ (a gift of Marion Merrell Dow, Cincinnati, OH, USA) was dissolved in ethanol and then brought up to a solution of $0.9 \%$ ethanol with isotonic saline. The vehicle solution was saline containing $0.9 \%$ ethanol. Injections were given S.c. in the scapular region at $1700 \mathrm{~h}$. Standard powdered laboratory chow (Prolab, Purina, St Louis, MO, USA) and water were freely available. Animals and food containers were weighed daily.

On day 42 a polyvinyl catheter (Dural Plastics Ltd, Auburn, Australia) was implanted under brevital (sodium methohexital, Eli Lilly, Indianapolis, IN, USA) anesthesia into the right atrium through the right external jugular vein. The heparin-filled catheter was tunnelled under the skin to exit dorsally, between the shoulder blades. The catheter was plugged and the animals kept on a heating pad until being returned to their cages. Blood samples for determination of $\mathrm{GH}$ pulsatility were taken via an intra-atrial catheter on day 46. The indwelling catheter was attached to a $50 \mathrm{~cm}$ polyvinyl extension by a piece of stainless steel tubing. The animals were allowed to adapt to the polyvinyl extensions for approximately $30 \mathrm{~min}$. Beginning at
$1030 \mathrm{~h}$, samples were collected every $10 \mathrm{~min}$ for $6 \mathrm{~h}$. Blood was withdrawn into heparin-treated $1.0 \mathrm{ml}$ syringes. Plasma was immediately collected after centrifugation, the red blood cells resuspended in saline, and returned to the animal after the subsequent sample. The initial blood sample was replaced with saline. This protocol was approved by the Institutional Animal Care and Use Committee (IACUC) of Virginia Commonwealth University. All samples were stored at $-20^{\circ} \mathrm{C}$ until assay for $\mathrm{GH}$ by RIA.

The assays were performed using RIA kits provided by the National Hormone and Pituitary Program of the National Institute of Diabetes, Digestive and Kidney Diseases (Bethesda, MD, USA) and Dr A F Parlow. The reference preparation was rat GH RP-2, and intra- and interassay coefficients of variation were 6.9 and $9.8 \%$ at 1.0 and $0.625 \mathrm{ng}$ per tube respectively.

Mean half-life, mean frequency of GH secretory pulses, mean GH secretory pulse amplitude (maximal rate attained per burst), mean GH secretory burst area (mass) and mean total GH secretion were calculated and analyzed by multi-parameter deconvolution of the plasma hormone concentrations according to the method of Veldhuis and Johnson $(38,39)$. Small pulses contributing less than $5 \%$ to the total secretion of a respective animal were excluded from further analyses. Intergroup comparisons were done by a Kruskal-Wallis test with a Mann-Whitney test for further testing in case of significance (JMP/SAS Institute, Cary, NC, USA).

\section{Results}

During the control period preceding treatment, all animals showed comparable weight gain (Table 1). During the treatment period, weight gain was slightly lower in the CTRL group in comparison to the preceding period of observation. This was mainly due to lack of weight gain peri-operatively. The two glucocorticoid groups showed significant reductions in weight gain. The DFZ group maintained about $28 \%$ of the CTRL mean daily weight gain $(1.3 \pm 0.4 \mathrm{~g} /$ day and $4.8 \pm$ $0.3 \mathrm{~g} /$ day respectively (S.E.M.)). The CORT group gained

Table 1 Weight gain, food intake, food efficiency and final weight of thymus for CORT-treated ( $5 \mathrm{mg} /$ day), DFZtreated $(0.15 \mathrm{mg} /$ day $)$ and CTRL rats. Values are means \pm S.E.M.

\begin{tabular}{lccc}
\hline & CTRL & CORT & DFZ \\
\hline Number of animals & 12 & 9 & 9 \\
Daily weight gain (g/day) & & & \\
$\quad$ Control period & $7.8 \pm 0.5$ & $8.5 \pm 0.7$ & $8.3 \pm 0.4$ \\
$\quad$ Treatment period & $4.8 \pm 0.3^{\mathrm{a}}$ & $0.1 \pm 0.5^{\mathrm{b}}$ & $1.3 \pm 0.4^{\mathrm{c}}$ \\
Food intake (g/day/100 g BW) & $10.1 \pm 0.30$ & $9.8 \pm 0.28$ & $9.8 \pm 0.29$ \\
Food efficiency (g weight gain/g food intake) & $0.31 \pm 0.02^{\mathrm{a}}$ & $0.02 \pm 0.05^{\mathrm{b}}$ & $0.06 \pm 0.05^{\mathrm{b}}$ \\
Thymus/BW $(\mathrm{g} / 100 \mathrm{~g})$ & $275 \pm 10^{\mathrm{a}}$ & $62 \pm 12^{\mathrm{b}}$ & $47 \pm 11^{\mathrm{b}}$ \\
\hline
\end{tabular}

Superscripts denote significant differences $(P<0.05)$ by Kruskal-Wallis/Mann-Whitney test between groups not sharing the same letter in any one row. 
Table 2 Deconvolution analysis for all derived parameters (mean \pm S.E.M.)

\begin{tabular}{lccc}
\hline & CTRL & CORT & DFZ \\
\hline Number of animals & 12 & 9 & 9 \\
GH half-life (min) & $12.9 \pm 1.2$ & $14.5 \pm 1.9$ & $11.7 \pm 1.2$ \\
GH production rate $(\mathrm{ng} / \mathrm{ml} / 6 \mathrm{~h})$ & $265 \pm 24$ & $207 \pm 46$ & $296 \pm 43$ \\
Number of pulses $(\mathrm{n} / 6 \mathrm{~h})$ & $3.8 \pm 0.3^{\mathrm{a}}$ & $5.8 \pm 0.3^{\mathrm{b}}$ & $4.2 \pm 0.5^{\mathrm{a}}$ \\
Interval (min) & $69 \pm 4.5^{\mathrm{a}}$ & $47 \pm 2.6^{\mathrm{b}}$ & $53 \pm 4.5^{\mathrm{b}}$ \\
Mass secretion per burst $(\mathrm{ng} / \mathrm{ml} / \mathrm{burst})$ & $73 \pm 7.3^{\mathrm{a}}$ & $38 \pm 9.5^{\mathrm{b}}$ & $96 \pm 31^{\mathrm{a}}$ \\
Amplitude $(\mathrm{ng} / \mathrm{ml} / \mathrm{min})$ & $19 \pm 6.6$ & $9.8 \pm 2.4$ & $31 \pm 15.5$ \\
\hline
\end{tabular}

Superscripts denote significant differences $(P<0.05)$ by Kruskal-Wallis/Mann-Whitney test between groups not sharing the same letter in any one row.

weight at a rate of only $2.5 \%$ of that of the CTRL $(0.1 \pm 0.5 \mathrm{~g} /$ day). As shown in Table 1 , daily weight gain was significantly different among all three groups during the treatment period. At the same time, food intake did not differ among groups during the control or treatment periods. In this respect, food efficiency ( $\mathrm{g}$ body weight gained/g food consumed) was reduced in the two treatment groups compared with CTRL animals. Although mean food efficiency was three times higher in the DFZ group in comparison to CORT animals, no statistical difference could be proven due to the high variability (Table 1 ).

Thymus weights are also shown in Table 1. The weight of the thymus, adjusted to $100 \mathrm{~g}$ body weight (BW), was significantly and equally reduced in both glucocorticoid groups. The lack of difference between thymus weights of the CORT- and the DFZ-treated animals supported the previous finding (31) that $5 \mathrm{mg}$ CORT were essentially equal to $0.15 \mathrm{mg}$ DFZ with respect to thymolytic activity. Side-effects of treatment other than growth disturbances, especially polyuria, were not observed.

During the blood collection experiments, three animals of each glucocorticoid group were excluded because of catheter malfunction. In the remaining successful collections, mean $\mathrm{GH}$ concentrations were $15.7 \pm 1.8 \mathrm{ng} / \mathrm{ml}$ in CTRL, $12.6 \pm 2.1$ in CORT and $17.8 \pm 2.0$ in the DFZ group. There were no differences among the three groups. Exclusion of minor pulses (less than $5 \%$ of total secretion) reduced the percentage of total secretion remaining in the analyses only to a minor extent. The precise remaining percentages of total secretion were: CTRL, $90.8 \pm 2.4 \%$; CORT, $94.9 \pm$ $1.4 \%$; DFZ, $91.9 \pm 2.9 \%$ (no significant differences among the groups).

Analyses of the specific parameters of pulsatile GH secretion by deconvolution revealed that significant changes had occurred during CORT treatment, while changes during DFZ were relatively mild. The half-life of plasma GH was not affected by glucocorticoid treatment (Table 2). Likewise, there were only marginal changes in total GH production among the groups. The absolute value for the CORT group was lower in comparison to the DFZ and CTRL groups, but the differences were not significant $(P=0.07$, Table 2$)$.
Probably more important than the above data, the pattern of GH pulsatility was significantly alter ed by the glucocorticoids. Significantly more detectable GH pulses per $6 \mathrm{~h}$ occurred in the CORT group than in the DFZ or CTRL group (Fig. 1, Table 2). Both glucocorticoids shortened the intervals between secretory bursts. In CTRL animals, the interval between bursts was $69.3 \pm$ $4.5 \mathrm{~min}$. In DFZ rats this was reduced to $53.0 \pm 4.5 \mathrm{~min}$ and in CORT rats it was lowest with $47.0 \pm 2.6 \mathrm{~min}$ (Fig. 1). The reduction in interpulse intervals in both treatment groups in comparison to CTRL was significant ( $P=0.0006$ for CORT and $P=0.048$ for DFZ). There was no difference between DFZ and CORT in regard to interval of the secretory bursts. The mass of GH secreted per burst was reduced in CORT to $52 \%$ of the respective control value (Table 2). DFZ did not significantly alter the mass of $\mathrm{GH}$ secreted per burst in comparison to CTRL. In this respect, CORT led to a marked and significant reduction in the mass per secretory burst in comparison to that of both of the other groups.

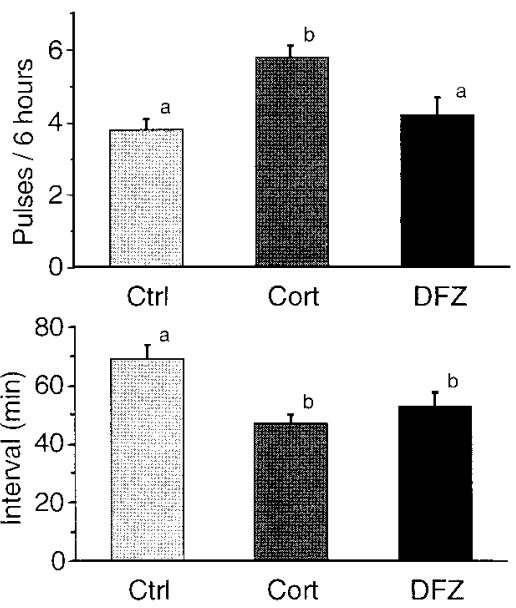

Figure 1 The mean number of secretory pulses ( \pm S.E.M.) occurring per $6 \mathrm{~h}$ and the interval between these pulses as derived by deconvolution analysis. Different superscripts denote significant differences $(P<0.05)$ by Kruskal-Wallis/Mann-Whitney test between groups not sharing the same letter. Thus, for pulses, Ctrl and DFZ are not different, because they share the letter ' $a$ '. Cort is different from the other two groups, because they do not bear the letter 'b'. 
A similar, although not significant, pattern was observed for the pulse amplitude, which was highest in the DFZ animals and lowest in the CORT group. The CTRL group showed an intermediate pulse amplitude (Table 2). Due to high variability, however, these data failed to reach statistical significance.

\section{Discussion}

Glucocorticoids penetrate the brain and pituitary gland, and have been shown to affect DNA transcription of the $\mathrm{GH}$ gene (40). DFZ is assumed to penetrate less into the brain because it is more hydrophilic $(24,25)$. Autoradiographic findings in rats after DFZ injection, where no DFZ could be detected in the central nervous system support this concept (26).

DFZ is a relatively new glucocorticoid with presumably fewer side-effects. Preliminary human studies, and at least one rat study, demonstrate beneficial effects of DFZ in terms of growth $(29,31,41,42)$. In the present study, growth rate was higher in the DFZ group than in the CORT group.

Pulsatile GH secretion was markedly affected in glucocorticoid-treated animals. The number of detectable $\mathrm{GH}$ pulses during the $6 \mathrm{~h}$ period was significantly increased in the CORT group, and only slightly, but not significantly, elevated in the DFZ animals. Most studies report intervals between major secretory events of $3 \mathrm{~h}$ for male rats after 30 days of age (43-45). Those studies were not based on deconvolution analyses, and included 'volleys' (multiple medium-sized peaks) in each of the major secretory events. By counting all individual secretory events as separate episodes, Martin et al. (46) described intervals of $68 \mathrm{~min}$ for normal rats. This is in very close agreement with the present data for CTRL animals, where a mean interval of 69 min was found. In both treatment groups the interval between pulses was decreased.

The mass of GH secreted per burst was significantly reduced, and total $\mathrm{GH}$ production was lower in the CORT but not in the DFZ group in comparison with CTRL. The intergroup pattern of the mean amplitudes of the secretory bursts correlated with the above changes, but varied widely, raising some concern in interpreting this aspect of the data. In general, amplitudes of pulses were relatively low. The peak heights of GH secretion are known to be affected by the pubertal status of the animals (44), with peaks getting higher the more puberty advances. This may have influ enced our results, although pubertal status was not assessed. Thus, maximal GH secretory activity was suppressed by CORT, while DFZ did not exhibit this effect.

However, the marked growth failure in the DFZ group is in sharp contrast to the relatively minor change observed in the total GH secretion of these animals. This suggests that total GH secretion is only one aspect in the pathophysiology of growth failure during glucocorticoid treatment, and that attenuated $\mathrm{GH}$ pulse height in combination with increased pulse frequency may contribute to the growth failure. This interpretation would agree with other studies that indicate the critical importance of the pulsatile pattern of $\mathrm{GH}$ secretion to the typically accentuated growth rate in males of many species. Further studies will be necessary to determine the importance of GH pulsatility to actual growth in glucocorticoid-treated animals, as well as the importance of potential changes in $\mathrm{GH}$ receptor abundance and activity, and insulin-like growth factor-I responsiveness to $\mathrm{GH}$.

Schäfer et al. (47) demonstrated comparable changes in $\mathrm{GH}$ secretion in children after kidney transplantation under glucocorticoid treatment. Total GH secretion and secretory mass per burst were reduced, while the number of pulses was increased in prepubertal boys. These parameters correlated with the applied dose of glucocorticoid. Extrapolation of our animal data to humans should be done with the utmost caution. Nevertheless, the similarities to the cited results and our findings with a conventional glucocorticoid, and the striking difference between DFZ and CORT, all point towards a similar potential benefit in $\mathrm{GH}$ secretion for humans under DFZ therapy.

In summary, the present data support the possibility that DFZ affects central nervous regulation of $\mathrm{GH}$ secretion less than does CORT. While CORT was thymolytic, suppressed growth, and altered the pulsatile mode of GH secretion, DFZ was thymolytic to the same degree, but inhibited growth and modified the pattern of GH secretion to a lesser degree. In this respect, DFZ may be considered to have a potent immunosuppressive effect with somewhat less growth inhibitory capacity.

\section{Acknowledgements}

$\mathrm{KL}$ was supported by a research grant from the Deutsche Forschungsgemeinschaft (La 789-1/2), RCDA \#1KO4 HD00634 (from NICHD, NIH, Bethesda, MD, USA (J DV), the Baxter Health Care Corp. (Roundlake, IL, USA) (J DV), and the NSF Center for Biological Timing (J DV). Other support was provided by an MCV/ VCU A D Williams grant (J CM C). We thank Dr Helen Morris of Marion Merrell Dow for the gift of deflazacort, and the National Hormone and Pituitary Program of NIDDK and Dr A F Parlow for the GH RIA kits. The authors would also like to express their gratitude to Ms Paula Azimi, Ms Whitney Gredig and Ms Linda Benson for their technical assistance.

\section{References}

1 Foote KD, Brocklebank JT \& Meadow SR. Height attainment in children with steroid-responsive nephrotic syndrome. Lancet 19852 917-919.

2 Blodgett FM, Burgin L, Lezzoni D, Gribetz D \& Talbot NB. Effects of prolonged cortisone therapy on the statural growth, skeletal maturation and metabolic status of children. N ew England Journal of M edicine 1956254 637-641. 
3 Fleisher DS, McCrory WW \& Rapoport M. The effects of intermittent doses of adrenocortical steroids on the statural growth of nephrotic children. Journal of Pediatrics 196057192 198.

4 Woodward CJH \& Emery PW. Energy balance in rats given chronic hormone treatment. B ritish Journal of Nutrition 198961 445-452.

5 Mosier HDJ \& Jansons RA. Growth hormone during catch-up growth and failure of catch-up growth in rats. Endocrinology 197698 214-219.

6 Krieg RJ Jr, Niimi K, Chan JCM, Santos F, Hanna JD \& Poletti LF. Cortisone effects on growth, food efficiency, and in vitro growth hormone release. Kidney International 199139 1135-1139.

7 Brattin WJ \& Portanova R. Effect of glucocorticoid levels in vivo on growth hormone biosynthesis. M olecular and Cellular Endocrinology $19791519-27$.

8 Kohler PO, Bridson WE \& Rayford PL. Cortisol stimulation of growth hormone production by monkey adenohypophysis in tissue culture. B iochemical and Biophysical Research Communications 196833 834-840.

9 Evans RM, Birnberg NC \& Rosenfeld MG. Glucocorticoid and thyroid hormones transcriptionally regulate growth hormone gene expression. Proceedings of the National Academy of Sciences of the USA $1982797659-7663$.

10 Spindler SR, Mellon SH \& Baxter JD. Growth hormone gene transcription is regulated by thyroid and glucocorticoid hormones in cultured rat pituitary tumor cells. Journal of Biological Chemistry 1982257 11627-11632.

11 Shapiro LE, Samuels HH \& Yaffe BM. Thyroid and glucocorticoid hormones synergistically control growth hormone mRNA in cultured GH 1 cells. Proceedings of the N ational A cademy of Sciences of the USA 197875 45-49.

12 Nakagawa K, Ishizuka T, Obara T, Matsubara M \& Akikawa K. Dichotomic action of glucocorticoids on growth hormone secretion. Acta Endocrinologica 1987116 165-171.

13 Ceda GP, Davis RG \& Hoffman AR. Glucocorticoid modulation of growth hormone secretion in vitro. Evidence for a biphasic effect on GH-releasing hormone mediated release. Acta Endocrinologica 1987114 465-469.

14 Yu LY, Tushinski RJ \& Bancroft FC. Glucocorticoid induction of growth hormone synthesis in a strain of rat pituitary cells. Journal of Biological Chemistry 1977252 3870-3875.

15 Michel $D$, Lefevre $G \&$ Labrie $F$. Dexamethasone is a potent stimulator of growth hormone-releasing factor-induced cyclic AMP accumulation in the adenohypophysis. LifeSciences 198435 597-602.

16 Wehrenberg WB, Baird A \& Ling N. Potent interaction between glucocorticoids and growth hormone-releasing factor in vivo. Science 1983221 556-557.

17 Pralong FP, Miell JP, Corder R \& Gaillard RC. Dexamethasone treatment in man induces changes in 24-h growth hormone (GH) secretion profile without altering total $\mathrm{GH}$ released. Journal of Clinical Endocrinology and M etabolism 199173 1191-1196.

18 Giustina A, Buffoli MG, Bussi AR, Doga M, Girelli A, Pizzocolo G et al. Comparative effect of clonidine and growth hormone (GH)releasing hormone on $\mathrm{GH}$ secretion in adult patients on chronic glucocorticoid therapy. Hormone and M etabolic Research 199224 240-243.

19 Mosier HDJ \& Jansons RA. Increase in pulsatile secretion of growth hormone during failure of catch-up growth following glucocorticoid-induced growth inhibition. Proceedings of the Society for Experimental Biology and M edicine 1985178 457-461.

20 Nathansohn G, Pasqualucci CR, Radaelli P, Schiatti P, Selva D \& Winters $G$. Steroids possessing nitrogen atoms. Some pharmacological and chemico-physical aspects of a new class of active corticoids: [17a, 16a-d]-oxazolino-steroids. Steroids 196913 365-381.

21 Assandri A, Buniva G, Martinelli E, Perazzi A \& Zerilli L. Pharmacokinetics and metabolism of deflazacort in the rat, dog, monkey and man. Advances in Experimental M edicine and Biology $19841719-23$.
22 Martinelli E, Ferrari P, Ripamonti A, Tuan G, Perazzi A \& Assandri A. Metabolism of deflazacort in the rat, dog and man. Drug M etabolism and Disposition 19797 335-339.

23 Assandri A, Ferrari P, Perazzi A, Ripamonti A, Tuan G \& Zerilli L. Disposition and metabolism of a new steroidal anti-inflammatory agent, deflazacort, in cynomolgus monkeys. Xenobiotica 198313 185-196.

24 Hahn BH, Pletscher LS \& Muniain M. Immunosuppressive effects of deflazacort - a new glucocorticoid with bone-sparing and carbohydrate-sparing properties: comparison with prednisone. Journal of Rheumatology 19818 783-790.

25 LoCascio V, Francia G, Davi MV, Olivieri M, Adami S, Cominacini L et al. Effect of deflazacort on growth hormone response to insulin tolerance test. Hormone and M etabolic Research 199224 333- 335.

26 Alessandro A, Antonio P, Giuseppe B \& Valeria P. Disposition of a new steroidal anti-inflammatory agent, deflazacort, in rat, dog and man. European Journal of Drug M etabolism and Pharmacokinetics 19805 207-215.

27 Aicardi G, Milani S, Imbimbo B, Vignolo M, Di Battista E, Gusmano $R$ et al. Comparison of growth retarding effects induced by two different glucocorticoids in prepubertal sick children: an interim long-term analysis. Calcified Tissue International 199148 283-287.

28 Balsan S \& Tieder M. Linear growth in patients with hypophosphatemic vitamin D-resistant rickets: influence of treatment regimen and parental height [see comments]. Journal of Pediatrics $1990116365-371$.

29 Loftus J, Allen R, Hesp R, David J, Reid DM, Wright DJ et al. Randomized, double-blind trial of deflazacort versus prednisone in juvenile chronic (or rheumatoid) arthritis: a relatively bonesparing effect of deflazacort. Pediatrics 199188 428-436.

30 Ferraris JR, Day PF, Gutman R, Granillo E, Ramirez J, Ruiz S \& Pasqualini T. Effect of therapy with a new glucocorticoid, deflazacort, on linear growth and growth hormone secretion after renal transplantation. Journal of Pediatrics 1992 121 809-813.

31 Latta K, Krieg RJ Jr, Chan W, Hisano S \& Chan JCM. Effects of deflazacort and cortisone on body growth, thymus weight, and gene expression of growth related proteins in the rat. European Journal of Endocrinology 1994 131 652-657.

32 Galliani G, A ssandri A, Luzzani F, Schiatti P \& Glässer A. Studies of the thymus-regressive effects of glucocorticoids in the rat and the hamster. Calcified Tissue International 198234587.

33 Guenther HL, Felix R \& Fleisch H. Comparative study of deflazacort, a new synthetic corticosteroid, and dexamethasone on the synthesis of collagen in different rat bone cell populations and rabbit articular chondrocytes. Calcified Tissue International $198436145-152$.

34 Schiatti P, Selva D, Barone D, Restelli A \& Glasser A. Antiinflammatory activity and other pharmacological properties of 11 beta, 21-dihydroxy-2'-methyl-5' beta H-pregna-1,4 dieno[17,16-d] oxazole 3, 20-dione-21-acetate (Deflazacort). Arzneimittelforschung $1980301543-1549$.

35 Luzzani F, Barone D, Galliani $G \&$ Glasser A. Ex vivo binding to glucocorticoid receptors in the thymus of the adrenalectomized rat. European Journal of Pharmacology 198387 61-66.

36 Gray RE, Doherty SM, Galloway J, Coulton L, de Broe M \& Kanis A. A double-blind study of deflazacort and prednisone in patients with chronic inflammatory disorders. Arthritis and Rheumatism 199134 287-295.

37 Lund B, Egsmose C, Jorgensen S \& Krogsgaard MR. Establishment of the relative antiinflammatory potency of deflazacort and prednisone in polymyalgia rheumatica. Calcified Tissue International 198741 316-320.

38 Veldhuis JD, Carlson ML \& Johnson ML. The pituitary gland secretes in bursts: appraising the nature of glandular secretory impulses by simultaneous multiple-parameter deconvolution of plasma hormone concentrations. Proceedings of the National Academy of Sciences of the USA 198784 7686-7690.

39 Veldhuis JD \& Johnson ML. Deconvolution analysis of hormone data. M ethods in Enzymology 1992210 539-575. 
40 Tushinski RJ, Sussman PM, Yu LY \& Bancroft FC. Pregrowth hormone messenger RNA: glucocorticoid induction and identification in rat pituitary cells. Proceedings of the National A cademy of Sciences of the USA 197774 2357-2361.

41 Balsan S, Steru D, Bourdeau A, Grimberg R \& Lenoir G. Effects of long-term maintenance therapy with a new glucocorticoid, deflazacort, on mineral metabolism and statural growth. Calcified Tissue International 198740 303-309.

42 Ferraris JR \& Pasqualini T. Therapy with a new glucocorticoid: effect of deflazacort on linear growth and growth hormone secretion in renal transplantation. Journal of Rheumatology 1992 37 (Suppl) 43-46.

43 Terry LC, Saunders A, Audet J, Willoughby JO, Brazeau P \& Martin $J B$. Physiologic secretion of growth hormoneand prolactin in male and female rats. Clinical Endocrinology 19776 (Suppl) 19S-28S.

44 Gabriel SM, Roncancio JR \& Ruiz NS. Growth hormone pulsatility and the endocrine milieu during sexual maturation in male and female rats. Neuroendocrinology 199256 619-628.
45 Tannenbaum GS \& Martin JB. Evidence for an endogenous ultradian rhythm governing growth hormone secretion in the rat. Endocrinology 197698 562-569.

46 Martin JB, Renaud LP \& Brazeau PJ. Pulsatile growth hormone secretion: suppression by hypothalamic ventromedial lesions and by long-acting somatostatin. Science 1974186 538-540.

47 Schäfer F, Veldhuis JD, Stanhope R, Jones J \& Schärer K. Alterations in growth hormone secretion and clearance in peripubertal boys with chronic renal failure and after renal transplantation. Cooperative study group of pubertal development in chronic renal failure. Journal of Clinical Endocrinology and M etabolism 199478 1298-1306.

Received 3 August 1998

Accepted 4 January 1999 